no sentido de reverter os desarranjos fisiológicos, diminuindo, assim, o risco de se evoluir com múltiplas disfunções orgânicas. Por fim, deve-se ressaltar que todo o tratamento disponível para essa população tem que ser adequadamente oferecido e que a rhAPC complementa de forma eficaz, mas não substitui aquilo que temos feito atualmente.

\section{Eliézer Silva}

Luiz francisco Poli de Figueiredo

\section{Referências}

I. Bernard GR, Vincent LL, Laterre PF, La Rosa SP, Dhainaut JF, Lopez - Rodriguez A, et al. Recombinant human protein $C$ worldwide evaluation in severe sepsis (PROWESS) study group. Efficacy and safety of recombinant human activated protein $\mathrm{C}$ for severe sepsis. N Engl J Med 200I; 344:699-709.

2. Bernard GR, Ely EW, Wright T], Fraiz J, Stasek JR, Russell JA, et al. Safety and dose relationship of recombinant human activated protein $\mathrm{C}$ for coagulopathy in severe sepsis. Crit Care Med 2001;29:205I-9.

3. Ely EW, Bernard GR, Vincent JL. Activated protein $C$ for severe sepsis. N Engl J Med 2002;347:1035-6.

\section{Obstetricia}

\section{QuAL É A CONDUTA ATUAL NO ÓBITO FETAL?}

Considerando-se que o produto da concepção se define como feto a partir de 10 semanas de gestação, o óbito fetal (OF) seria toda a morte a partir desta idade gestacional.A Organização Mundial da Saúde define o OF como a "morte do feto antes da completa expulsão ou extração do produto da concepção do corpo da mãe, independente da duração da gravidez". O Centro Nacional de Estatística da Saúde dos Estados Unidos conceitua morte fetal aquela ocorrida a partir de 20 semanas de gestação. Da mesma forma, para acomodar os interesses burocráticos, a maioria das estatísticas nacionais sobre $\mathrm{o}$ assunto preferem defini-lo a partir de 20 semanas de gestação ou peso no nascimento maior que 500 gramas. A incidência é muito variável nos diversos serviços universitários, oscilando entre $0,2 \%$ a $4,5 \%$. Em estudo realizado no
Hospital das Clínicas da FMUSP, Schupp etal., 2000 , observaram incidência de $4,5 \%$ no período de 1993 a 1998. A assistência obstétrica, nesses casos, abarca atenção global à paciente em virtude de envolver intensamente os aspectos emocionais, um luto a ser elaborado. Inclui também a busca da etiologia que se faz necessária, uma vez que existe grande multiplicidade de fatores predisponentes e desencadeantes desse infausto acontecimento. Dessa forma, as perspectivas futuras do provir obstétrico podem ser clarificadas à luz de investigações individualizadas, com respaldo em conhecimentos teóricos/científicos consolidados. Quanto à resolução dos casos, embora $75 \%$ a $90 \%$ das gestantes com diagnóstico de óbito fetal evoluírem para parto espontâneo em duas semanas, poucas pacientes aceitam aguardar passivamente $o$ evento, solicitando ao médico uma conduta ativa para uma abreviação rápida do quadro. Nessa situação, é indispensável ponderar os riscos e os benefícios oriundos de uma intervenção ativa, no intuito de se otimizar os resultados, com mínimas seqüelas, orgânicas e emocionais. A complexidade na resolução reside na eficácia dos métodos disponíveis, pois geralmente 0 OF ocorre durante o segundo ou início do terceiro trimestre da gestação, quando a cérvix está ainda imatura. Em gestantes sem cicatriz uterina prévia e com uma altura uterina de até $26 \mathrm{~cm}$, utilizamos misoprostol $200 \mu \mathrm{g}$ via oral e $200 \mu \mathrm{g}$ via vaginal de ataque e após $200 \mu \mathrm{g}$ via vaginal a cada 4 horas até o parto, com índice de sucesso de $90 \%$ e tempo médio de indução de 17,7 horas com desvio padrão de I4,2 horas. Se a gestante apresentar uma cicatriz uterina prévia, utilizamos o mesmo esquema, porém com a dose de misoprostol pela metade, isto é $100 \mu \mathrm{g}$. Nos casos com idade gestacional mais avançada, constatado por uma altura uterina acima de $26 \mathrm{~cm}$, utilizamos para indução do parto a ocitocina em dosagem semelhante à indução de um parto normal, com tempo médio de indução de 39,9 horas, com desvio padrão de 50,2 horas. Já nos casos em que a paciente apresenta mais de uma cicatriz uterina prévia, temos conduta personalizada para cada caso. Após o parto sempre há a necessidade de avaliar se ainda existem restos ovulares e nos casos em que isso ocorre deve ser realizada a curetagem uterina. Nos casos em que se adota a conduta expectante, é importante a monitorização de coagulopatia, um evento que aparece na incidência de até $25 \%$ após quatro semanas do óbito.

\section{Tânia Regina Schupp \\ Seizo Miyadahira Marcelo Zugaib}

\section{Referências}

I. Chiswick ML. Commentary on current World Health Organization definitions used in perinatal statistics. Br JObstet Gynaecol I986; 93:1236-8.

2. Tricomi V, Kohl SG. Fetal death in utero. Am J Obstet Gynecol 1957; 74:1092-7.

3. Bugalho A, Bique $C$, Machungo F, Faundes A. Induction of labor with intravaginal misoprostol in intrauterine fetal death. Am JObstet Gynecol 1990; 163:540-2.

4. Schupp TR, MiyadahiraS, KahhaleS, Zugaib $M$. Management of pregnancy in a university hospital: a 6-year study. Rev Hosp Clin Fac Med São Paulo 2000; 55:137-44.

5. Zugaib M, Bittar RE. Protocolos Assistencias da Clínica Obstétrica da Faculdade de Medicina da Universidade de São Paulo. São Paulo: Atheneu; 1996. p. 189-9I.

\section{Pediatria \\ O QUE DEVO OBSERVAR NA REINDICAÇÃo DE TERAPÊUTICA ANTIMICROBIANA?}

$O$ uso de antimicrobiano deve ser observado no que diz respeito ao efeito de seleção e da disseminação dessa seleção de cepas com características especiais. Hoje, os agentes bacterianos que produzem $\beta$ Lactamase (PBL) merecem atenção especial, pois limitam 0 tratamento antimicrobiano. A terapêutica empírica inicial, em muitas circunstâncias, deve ser repensada com base nos dados da história de uso de antimicrobiano pelo paciente. Assim é que acumulam-se na literatura evidências a partir de que, introduzida uma droga $\beta$ Lactâmica em um grupo de pacientes, rapidamente (ao fim da I ${ }^{\text {a }}$ semana) em $50 \%$ deles serão detectadas cepas $\mathrm{PBL}$, quando antes do uso do antibiótico 